\title{
Spray-drying microencapsulation of $\beta$-carotene by polysaccharide from yeast cell walls
}

\author{
Hien T. Do ${ }^{1}$, Tuyen C. Kha ${ }^{2 *}, \&$ Trang P. P. Huynh ${ }^{1}$ \\ ${ }^{1}$ Faculty of Biotechnology, Ho Chi Minh City University of Food Industry, Ho Chi Minh City, Vietnam \\ ${ }^{2}$ Faculty of Food Science and Technology, Nong Lam University, Ho Chi Minh City, Vietnam
}

\begin{abstract}
ARTICLE INFO
Research Paper

Received: August 30, 2019

Revised: September 20, 2019

Accepted: November 11, 2019

\section{Keywords}

$\beta$-carotene

Microencapsulation

Polysaccharide

Spray drying

Yeast cell wall

\section{* Corresponding author}

Kha Chan Tuyen

Email: khachantuyen@hcmuaf.edu.vn

ABSTRACT

It is well known that $\beta$-carotene plays an important role in human health. However, it is susceptibly degraded by environmental conditions including temperature, light and oxygen, due to its natural structure of conjugated double bonds chain. Polysaccharide (PS) from the yeast cell walls has appeared to be an excellent choice of encapsulating agent that can be used to encapsulate biologically active substances. Objective of this study was to investigate the effects of PS concentration (20,30, 40 and 50\%) compared to MD, high pressure homogenization time $(5,10,15,20 \mathrm{~min})$ and inlet air temperature of spray drying $\left(130,140,150,160^{\circ} \mathrm{C}\right)$ on microencapsulation yield (MEY), microencapsulation efficiency (MEE), moisture content (MC) and antioxidant capacity. The results showed that the highest values of MEY (354.4 $\mathrm{pg} / \mathrm{g}$ ) and MEE $(90.2 \%)$, the low value of MC $(7.0 \%)$ and antioxidant capacity $(69.07 \%)$ were successfully obtained at PS concentration of $30 \%(\mathrm{w} / \mathrm{v})$, homogenization of $15 \mathrm{~min}$ and inlet air temperature of $150^{\circ} \mathrm{C}$. Under those conditions, the encapsulated $\beta$-carotene powder was examined by scanning electron microscopy (SEM) and it is confirmed that the micro-particles had various sizes which are a typical characteristics of spray dried powders, spherical shapes and were free of cracks and pores. As a result, it can be concluded that $\beta$-carotene was successfully encapsulated in the PS and MD matrix and could then be easily incorporated into various foods.
\end{abstract}

Cited as: Do, H. T., Kha, T. C., \& Huynh, T. P. P. (2019). Spray-drying microencapsulation of $\beta$-carotene by polysaccharide from yeast cell walls. The Journal of Agriculture and Development 18(6), 49-57.

\section{Introduction}

Brewer's yeast is a by-product of brewery, of which a small portion is sold to livestock households for use as direct feed, and the rest is discarded into the environment or need to be treated at high cost. However, the composition of the yeast by-product contains a large amount of yeast cells, in which cell walls account for about 20$30 \%$ of dry biomass. The main components in the yeast cell wall are polysaccharides (PS), which include mannoproteins and $\beta$-glucan, accounting for $30-40 \%$ and $50-60 \%$, respectively, and a very small amount of chitin (Kogan \& Kocher, 2007). As a result, it is important to utilize the yeast by-product for food ingredient applications.

Microencapsulation of bioactive substances is one of the most effective methods applied in the food industry. Currently, there are various wall materials used for microencapsulation such as maltodextrin (MD), whey protein and gum. PS from yeast cells has been known as alternative wall material that can be used to encapsulate bioactive components for maintaining the stability of the bioactive compounds from sensitive environmental conditions such as temperature, $\mathrm{pH}$, 
light, and oxygen. Shi et al. (2008) studied using Saccharomyces cerevisiae's yeast cells to encapsulate resveratrol compounds. The results showed that after being absorbed into the yeast cell wall, resveratrol compound improved water solubility and chemical structure was kept stable and the biological activity was ensured. The research of Czerniak et al. (2015) on using yeast cells to encapsulate fish oil products showed that the microencapsulation could help products withstand the high temperatures during the drying process and prevent the oxygen diffusion from products and limit the oxidation of fish. Similarly, Sultana et al. (2018) reported that yeast cell walls can be effectively used to microencapsulate d-limonene essential oil. After the microencapsulation, the essential oil was more durable to temperature, which could be convenient for spray-drying to improve the quality of the resultant product from oxidation.

$\beta$-carotene is a food colorant and a highly bioactive substance which has been widely used in food industry. However, it is unstable when exposed to light, oxygen and temperature. Thus, encapsulation of $\beta$-carotene has been reported to effectively protect against the effects of the susceptible environment conditions. Loksuwan (2007) stated that $\beta$-carotene could be effectively encapsulated using spray drying. Kha et al. (2010) carried out the encapsulation of carotenoid compounds in Gac fruit (Momordica cochinchinensis) by spray-drying method with maltodextrin. The results indicated that the spray drying temperature significantly affected the reduction of carotenoids in the samples. If the drying temperature increased from 120 to $200^{\circ} \mathrm{C}$ antioxidant activity decreased from 0.14 to $0.08 \mathrm{mmol} \mathrm{TE} / \mathrm{g}$ powder and the microencapsulation efficiency reduced from $76.6 \%$ to $48.0 \%$. Another study of Pham-Hoang et al. (2018) reported that using yeast cells Yarrowia lipolytica to microencapsulate $\beta$-carotene demonstrated the highest encapsulation efficiency. In addition, the use of ultrasound assistance was reported to significantly improve the carotene encapsulation efficiency.

There is lack of information on encapsulation of $\beta$-carotene using PS as wall material in the published literature. Therefore, this study is aimed to investigate effects of PS concentration, homogenization time and inlet air temperature of spray drying on microencapsulation yield (MEY) and microencapsulation efficiency (MEE). In ad- dition, physical properties and antioxidant capacity of the encapsulated $\beta$-carotene powder were also evaluated and compared.

\section{Materials and Methods}

\subsection{Materials}

$\beta$-carotene (97\%) and DPPH (2,2-diphenyl1-picrylhydrazyl) were purchased from SigmaAldrich Pty. Ltd. All solvents used in this study were of analytical grade. PS was extracted from yeast by-product obtained from Saigon Brewery, Vietnam by combining ultrasonic and enzyme methods. Briefly, yeast by-product in the gelatious form was mixed with distilled water at ratio of $1: 3(\mathrm{w} / \mathrm{w})$, respectively, allowed to settle for 1 $\mathrm{h}$ and then decanted the upper layer and water. This step was performed in triplicate. The collected yeast residue (about $10 \mathrm{~g}$ ) was added $3 \%$ $(\mathrm{v} / \mathrm{w})$ protease enzyme and incubated at $45^{\circ} \mathrm{C}$ for $6 \mathrm{~h}$. Afterward, water $(40 \mathrm{~mL})$ was added, ultrasound treated for $10 \mathrm{~min}$ and centrifuged at 4500 rpm for $15 \mathrm{~min}$. The collected residue was washed with water three times, and centrifuged at 4500 rpm for $15 \mathrm{~min}$ to collect PS.

\subsection{Microencapsulation of $\beta$-carotene}

For core material, $\beta$-carotene was first dissolved and mixed thoroughly in the solution containing alcohol and acetone at ratio of 1:1 (w/w). For wall material preparation, maltodextrin (10 g) mixed with polysaccharide at different concentrations of $20,30,40$ and $50 \%(\mathrm{w} / \mathrm{v})$, and then the mixture was dissolved in $50 \mathrm{~mL}$ of $0.37 \%$ trehalose solution. For comparison, maltodextrin used as wall material was also prepared.

To create emulsions, the $\beta$-carotene solution $(10 \mathrm{~mL})$ was added dropwise to wall material solutions $(50 \mathrm{~mL})$ while mixing using homogenizer at $4200 \mathrm{rpm}$ for different times (5, 10, 15 and 20 min) to allow full incorporation. The stable solutions were spray-dried in a LabPlant SD-06 spray dryer (LabPlant UK Ltd., North Yorkshire, UK). The dryer was equipped with a two-fluid nozzle atomizer ( $0.5 \mathrm{~mm}$ diameter). The operating conditions of the spray drying were inlet temperatures of $130,140,150$ and $160^{\circ} \mathrm{C}$, outlet temperatures of $73-80^{\circ} \mathrm{C}$ and pressure of 2 bar, and the feed flow rate was about $200 \mathrm{~mL} / \mathrm{h}$. The obtained encapsulated powder was recovered from the collecting chamber. The powders were stored at $4^{\circ} \mathrm{C}$ 
in a vacuum bag until analysis (within $24 \mathrm{~h}$ ). The sample preparation was done in triplicate.

For stability test, after microencapsulation of $\beta$-carotene by spray drying, the encapsulated $\beta$ carotene powder was stored at different storage conditions including exposure to light and oxygen. The vacuum packaged powder (considered as relatively without air) was used as control. The external morphography of powder particles using scanning electron microscopy (SEM) and antioxidant capacity at different times of 4 and $8 \mathrm{~h}$ were evaluated. The commercial $\beta$-carotene powder was also used for comparison in terms of antioxidant capacity.

\subsection{Analytical methods}

\subsubsection{Microencapsulation Yield (MEY)}

The MEY was calculated as the amount of microencapsulated $\beta$-carotene in $1 \mathrm{~g}$ of spray dried powder (Paramera et al., 2011).

$\mathrm{MEY}=\frac{\text { Amount of microencapsulated } \beta \text {-carotene }}{\text { Amount of spray dried powder }}(\mathrm{\mu g} / \mathrm{g})$

$\beta$-carotene content determination: The content of $\beta$-carotene in the samples was determined by $\mathrm{UV}-\mathrm{V}$ is method by measuring absorbance at 450 $\mathrm{nm}$ wavelength and calculated according to BeerLambert law (Rodriguez-Amaya, 2001).

$\beta$-carotene content $=\frac{\text { Abs at } 450 \times \mathrm{y} \times 1000}{2620 \times 100}(\mathrm{mg})$

Where:

$\mathrm{y}(\mathrm{mL})$ is the total volume of measured solution

2620 is the molecular absorption factor

1000 is the conversion factor from $\mathrm{g}$ to $\mathrm{mg}$

\subsubsection{Microencapsulation efficiency (MEE)}

The MEE was calculated as the percentage between the amount of microencapsulated $\beta$ carotene and the initial amount of $\beta$-carotene (Pham-Hoang et al., 2018).

$\mathrm{MEE}=\frac{\text { Amount of microencapsulated } \beta \text {-carotene }}{\text { Initial amount of } \beta \text {-carotene }} \times 100(\%)$

Microencapsulated $\beta$-carotene content determination: Weighing $1 \mathrm{~g}$ of spray-dried powder and dissolving in $15 \mathrm{~mL}$ hexane, and then vortexing for $5 \mathrm{~min}$, and then centrifuging at $4500 \mathrm{rpm}$ for $5 \mathrm{~min}$, and finally obtaining the supernatant. The supernatant was measured at $450 \mathrm{~nm}$ wavelength to determine the surface $\beta$-carotene content. The blank sample was hexane.

Amount of microencapsulated $\beta$-carotene $=$ (Initial amount of $\beta$-carotene) - (Amount of surface $\beta$-carotene).
Determination of antioxidant capacity by DPPH method: According to Brand-Williams et al. (1995), DPPH was diluted at a concentration of $40 \mathrm{\mu g} / \mathrm{mL}$ with methanol. For the commercial carotene sample, the sample was dissolved to $0.15 \mathrm{mg} / \mathrm{mL}$ with hexane. About $2 \mathrm{~mL}$ of supernatant was added with $2 \mathrm{~mL}$ of DPPH solution, incubated for $30 \mathrm{~min}$ and finally determined the antioxidation capacity of the sample at $517 \mathrm{~nm}$ wavelength.

For the spray dried powder sample, the sample was dissolved in water, centrifuged at $5000 \mathrm{rpm}$ for $5 \mathrm{~min}$, and then collected the residue. The residue was continually dissolved with $10 \mathrm{~mL}$ of $1 \mathrm{M}$ buffer solution of sodium acetate for $20 \mathrm{~min}$. Next, about $10 \mathrm{~mL}$ of hexane added to obtain $\beta$ carotene concentration of $0.15 \mathrm{mg} / \mathrm{mL}$, then $2 \mathrm{~mL}$ $\mathrm{DPPH}$ was added. The samples were incubated at ambient temperature for $30 \mathrm{~min}$ and measured at $517 \mathrm{~nm}$ wavelength.

The percentage of free radical reduction of the sample was calculated as follows:

$$
\mathrm{I}(\%)=100 \times \frac{\mathrm{A}_{0}-\mathrm{A}_{1}}{\mathrm{~A}_{0}}
$$

Where:

$\mathrm{I}(\%)$ is the percentage of free radical reduction of the sample at $517 \mathrm{~nm}$

$\mathrm{A}_{0}$ : Absorbance of DPPH

$\mathrm{A}_{1}$ : Absorbance of the tested sample

The blank sample is a methanol solution

\subsubsection{Statistical analysis}

The independent experiments and subsequent measurements were done in triplicate. The results were presented as mean values with standard deviations. A one-way analysis of variance (including PS concentration, homogenization time and inlet air temperature) and LSD (least significant difference) were used to analyze the data using the Statgraphics centurion XVI software.

\section{Results and Discussion}

\subsection{The effect of wall material on microencap- sulation process}

Carrier (wall material) is an important ingredient affecting the microencapsulation process, including MEE and MEY. One of the most important characteristics of wall material includes non-reactive with the core, ability to encapsulate 
Table 1. The effect of polysaccharides (PS) content combined with maltodextrin on microencapsulation process

\begin{tabular}{cccc}
\hline $\begin{array}{c}\text { PS content } \\
(\%, \mathrm{w} / \mathrm{v})\end{array}$ & $\begin{array}{c}\text { Amount of } \\
\text { microencapsulated } \\
\beta \text {-carotene }(\mathrm{mg})\end{array}$ & $\begin{array}{c}\text { Microencapsulation } \\
\text { Yield }(\mathrm{\mu g} / \mathrm{g})\end{array}$ & $\begin{array}{c}\text { Microencapsulation } \\
\text { efficiency }(\%)\end{array}$ \\
\hline 20 & $2.958 \pm 0.01^{\mathrm{a}}$ & $197.60 \pm 0.07^{\mathrm{b}}$ & $75.65 \pm 0.92^{\mathrm{a}}$ \\
30 & $3.293 \pm 0.01^{\mathrm{b}}$ & $205.88 \pm 1.27^{\mathrm{b}}$ & $81.30 \pm 7.72^{\mathrm{b}}$ \\
40 & $3.289 \pm 0.02^{\mathrm{b}}$ & $173.95 \pm 0.64^{\mathrm{a}}$ & $80,55 \pm 8.55^{\mathrm{b}}$ \\
50 & $3.280 \pm 0.02^{\mathrm{b}}$ & $171.16 \pm 0.64^{\mathrm{a}}$ & $79.95 \pm 1.92^{\mathrm{b}}$ \\
\hline
\end{tabular}

The values in the same column followed by different superscripts $(\mathrm{a}-\mathrm{b})$ were significantly different $(P<0.05)$.

and maintain the core inside the microcapsule; and ability to provide maximum protection to the core against adverse conditions (Gharsallaoui et al., 2007; Nazzaro et al., 2012). It is highly desirable to achieve the highest ratio of the core (bioactive compounds) to the wall material. The concentration of the wall material was too high leading to an increase in the viscosity and difficult to spray-dry (Tonon et al., 2008). In this experiment used PS 20,30, 40 and $50 \%(\mathrm{w} / \mathrm{v})$ combined with MD to microencapsulate $\beta$-carotene by spray drying, inlet air temperature $150^{\circ} \mathrm{C}$, feed rate $200 \mathrm{~mL} / \mathrm{h}$, and pressure of $2 \mathrm{bar}$. The effect of PS concentration on MEE and MEY is shown in Table 1.

According to Table 1, the amount of PS being $20 \%$ was not enough to encapsulate all the $\beta$-carotene, indicated by low MEE. The largest amount of microencapsulated $\beta$-carotene and the highest MEE were $3.29 \mathrm{mg}$ and $81.30 \%$ respectively, when incorporated with $30 \%$ of PS. When increase in PS amount, up to $40 \%$ or $50 \%$ PS resulted in insignificantly decrease in the amount of $\beta$-carotene. It can be concluded that high content of PS of $30 \%$ could be enough for encapsulating $\beta$-carotene.

Wagner \& Warthesen (1995) performed the microencapsulation of carotene with MD powder. The results showed that about $38 \%$ of $\beta$-carotene was not encapsulated. Similarly, Loksuwan (2007) used MD by spray drying method to microencapsulate $\beta$-carotene and reported that the total amount of $\beta$-carotene accounted for $46.74 \%$ of the total weight of spray dried powder. It can be seen that only MD used as wall material was not effective, there is a need to combine with other wall materials. Sultana et al. (2018) encapsulated dlimonene by spray-drying method with MD and yeast cell walls and the results showed that about $82 \%$ of the d-limonene was retained in the MD and sodium caseinate matrix and $26 \%$ was re- tained in the yeast cell wall.

For comparison (Figure 1), the microencapsulation of $\beta$-carotene powder using PS and MD mixture as wall material had MEE reached up to $87.15 \%$, which was 1.5 times higher than that of powder using only MD (56.90\%). Furthermore, a higher moisture content of microencapsulated sample using only MD (8.3\%) was observed as compared to the ones using the mixture of PS combined with MD (MC of 7\%), resulting higher MY, which were $52.97 \%$ and $45.20 \%$, respectively. It is well known that higher moisture content could result in instability during storage.

It can be concluded that the mixture of PS and MD has shown excellent property of wall material for encapsulation of $\beta$-carotene. The microencapsulated $\beta$-carotene powder has ability to withstand the impacts of light and oxygen better than that of the free $\beta$-carotene form (without wall material). The reason is that the wall material containing PS ( $\beta$-glucan) could protect $\beta$-carotene and has a good antioxidant capacity.

According to Sun-Waterhouse et al. (2011), an appropriate selection of wall materials is very important. Generally, combinations of various encapsulating agents are required to effectively protect and control the bioactive compounds. Thus, combination of PS and MD to microencapsulate $\beta$-carotene, resulted in higher MEE than only MD. It is highly recommended that $30 \%$ PS in combination with MD (10 g) should be used to encapsulate $\beta$-carotene.

\subsection{The effect of homogenization time on the $\beta$-carotene microencapsulation process}

The homogenization has positively influenced stability of $\beta$-glucan in the solution and prevented the accumulation of $\beta$-glucan (Bzducha-Wróbel et al., 2014), and also reduced the size of the emulsion droplets. As such, the increase in the 


\section{曰PS + maltodex trin $\square$ Maltodextrin}

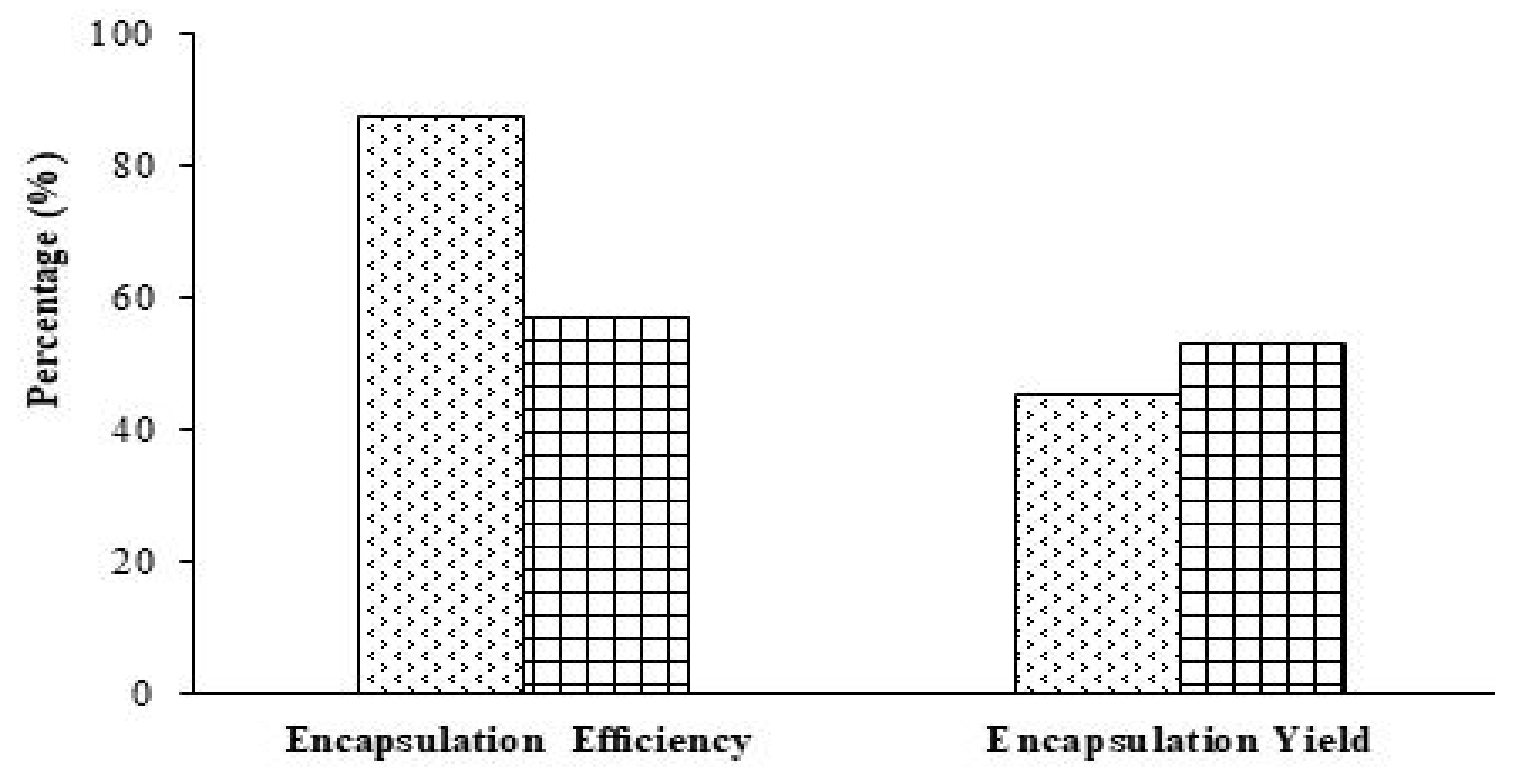

Figure 1. Microencapsulation efficiency and Microencapsulation yield of $\beta$-carotene using maltodextrin (MD) and the mixture of polysaccharides and MD.

Table 2. The effect of homogenization time on the $\beta$-carotene microencapsulation process

\begin{tabular}{cccc}
\hline $\begin{array}{c}\text { Homogenization } \\
\text { time }(\mathrm{min})\end{array}$ & $\begin{array}{c}\text { Amount of } \beta \text {-carotene } \\
\text { microencapsulated } \\
(\mathrm{mg})\end{array}$ & $\begin{array}{c}\text { Microencapsulation } \\
\text { Yield }(\mathrm{\mu g} / \mathrm{g})\end{array}$ & $\begin{array}{c}\text { Microencapsulation } \\
\text { Efficiency }(\%)\end{array}$ \\
\hline 5 & $4.658 \pm 0.47^{\mathrm{b}}$ & $226.0 \pm 22.63^{\mathrm{b}}$ & $78.2 \pm 7.85^{\mathrm{b}}$ \\
10 & $5.251 \pm 0.06^{\mathrm{c}}$ & $251.0 \pm 2.83^{\mathrm{c}}$ & $88.1 \pm 1.13^{\mathrm{bc}}$ \\
15 & $5.421 \pm 0.04^{\mathrm{c}}$ & $268.5 \pm 2.12^{\mathrm{c}}$ & $91.0 \pm 0.71^{\mathrm{c}}$ \\
20 & $3.910 \pm 0.07^{\mathrm{a}}$ & $188.5 \pm 3.54^{\mathrm{a}}$ & $65.6 \pm 1.13^{\mathrm{a}}$ \\
\hline
\end{tabular}

The values in the same column followed by different superscripts (a-c) were significantly different $(P<0.05)$.

contact area between the wall material and the carotene as well as the mass transfer and evaporation rate during the atomization are achievable (Shappley et al., 1998). As a result, higher MEY and MEE could be obtained. In this experiment, the most suitable homogenization time $(5,10,15$ and $20 \mathrm{~min}$ ) was tested and the results are shown in Table 2 .

When the homogenization time increased from 5 to $10 \mathrm{~min}$, the amount of microencapsulated $\beta$ carotene increased from $4.658 \mathrm{mg}$ to $5.251 \mathrm{mg}$. However, the amount of $\beta$-carotene in the encapsulated powder had no statistically significant difference when increasing the homogenization time from 10 to $15 \mathrm{~min}$ and even reduces to $3.910 \mathrm{mg}$ when the initial solution was homogenized for 20 min. The highest MEYs were obtained for the homogenization times of 10 and $15 \mathrm{~min}$, being
251.0 and $268.5 \mu \mathrm{g} / \mathrm{g}$, respectively. At $20 \mathrm{~min}$, the MEY was only $188.5 \mu \mathrm{g} / \mathrm{g}$. The highest MEEs were found to be $88.1 \%$ and $91 \%$ corresponding to the homogenization times of 10 and $15 \mathrm{~min}$, respectively. At $20 \mathrm{~min}$, the MEE decreased due to longer homogenization time, it may negatively affect the structure of the wall material (PS), leading to inefficient microencapsulation.

Trehalose is considered to be a polysaccharide protective agent against environmental stress conditions, keeping its structure from being changed during homogenization process. Trehalose also has another role in the better transmembrane transfer of carotene (Golovina et al., 2010). Thus, the homogenization time of $15 \mathrm{~min}$ for initial solution before spray drying should be carried out. 
Table 3. Effect of inlet spray drying temperature

\begin{tabular}{cccc}
\hline $\begin{array}{c}\text { Inlet temperature } \\
\left({ }^{\circ} \mathrm{C}\right)\end{array}$ & $\begin{array}{c}\text { Amount of } \\
\text { microencapsulated } \\
\beta \text {-carotene }(\mathrm{mg})\end{array}$ & $\begin{array}{c}\text { Microencapsulation } \\
\text { Yield }(\mathrm{\mu g} / \mathrm{g})\end{array}$ & $\begin{array}{c}\text { Microencapsulation } \\
\text { Efficiency }(\%)\end{array}$ \\
\hline 130 & $3.495 \pm 0.06^{\mathrm{b}}$ & $318.40 \pm 27.55^{\mathrm{ab}}$ & $79.7 \pm 1.27^{\mathrm{b}}$ \\
140 & $3.764 \pm 0.06^{\mathrm{c}}$ & $327.63 \pm 31.22^{\mathrm{ab}}$ & $86.6 \pm 2.47^{\mathrm{c}}$ \\
150 & $3.955 \pm 0.07^{\mathrm{d}}$ & $354.36 \pm 2.16^{\mathrm{b}}$ & $90.2 \pm 1.38^{\mathrm{c}}$ \\
160 & $3.240 \pm 0.95^{\mathrm{a}}$ & $267.02 \pm 35.58^{\mathrm{a}}$ & $73.9 \pm 2.12^{\mathrm{a}}$ \\
\hline
\end{tabular}

The values in the same column followed by different superscripts (a-c) were significantly different $(P<0.05)$.

\subsection{Effect of inlet temperature on the $\beta$ - carotene microencapsulation process}

The inlet temperature affects the water evaporation rate and film formation. When temperature is too low, the moisture of product is still high, so the particles easily stick to the drying chamber wall, resulting in decreasing efficiency. At higher inlet temperatures, the evaporation rate of water on the surface of the spray-dried powder is also higher, leading to a better formation of the film, so locked up well and higher protection of bioactive compounds, as a result, MEY and MEE are improved. However, when drying temperature is too high, it can flaw on the film. Thus, it reduces biological activity and loss of MEY and MEE (Kha et al., 2014). It is desirable to determine the most suitable spray drying temperature, and the effect of inlet temperature on the MEY and MEE is presented in Table 3.

Table 3 shows that when the inlet temperature increased from $130^{\circ} \mathrm{C}$ to $150^{\circ} \mathrm{C}$, the amount of microencapsulated $\beta$-carotene increased gradually for up to $12 \%$. The reason is higher temperature resulted in better film formation, which led to the increases in MEY and MEE. However, at $160^{\circ} \mathrm{C}$, the amount of microencapsulated $\beta$ carotene significantly decreased from $3.955 \mathrm{mg}$ to $3.240 \mathrm{mg}$, indicated by lower MEE and MEY.

According to Shu et al. (2006), high inlet temperature could disrupt the balance between water evaporation rate and film formation process, resulting in the disrupted membrane system of the microcapsules, and reducing the retention of $\beta$ carotene in the microcapsules. As a result, the MEY and MEE were decreased. Similar result was found in the report of Kha et al. (2010) who performed the encapsulation of carotenoid compounds in Gac fruit by spray drying method with MD. The results showed that the inlet temperature also affected the reduction of carotenoids in the samples. An increasing the inlet temperature from $120^{\circ} \mathrm{C}$ to $200^{\circ} \mathrm{C}$ resulted in a decrease in encapsulation efficiency and antioxidant capacity from $76.6 \%$ to $48.0 \%$ and 0.14 to $0.08 \mathrm{mmol} \mathrm{TE} / \mathrm{g}$ powder, respectively.

It can be concluded that inlet temperature is the most important parameter that could affect the MEY and MEE. For this study, the inlet temperature of $150^{\circ} \mathrm{C}$ should be chosen for better retention of $\beta$-carotene in the microencapsulated powder.

\subsection{Antioxidant capacity of the powder sam- ples}

In this study, antioxidant capacity of the commercial $\beta$-carotene and microencapsulated $\beta$ carotene powders under light and oxygen conditions was compared at different times (Figures 2 and 3). The antioxidant capacity of the commercial sample decreased sharply from $75.66 \%$ to $40.61 \%$ for the first $4 \mathrm{~h}$ (a decrease of about $35 \%$ ) and continued to decrease to $35.91 \%$ for the next $4 \mathrm{~h}$. However, the antioxidant capacity of the microencapsulated $\beta$-carotene sample decreased from $69.07 \%$ to $55.08 \%$ (a decrease of about $12 \%$ ) for the first $4 \mathrm{~h}$, and the antioxidant capacity decreased slightly for the next $4 \mathrm{~h}$. Thus, it can be concluded that the effect of light on the microencapsulated $\beta$-carotene powder was much lower than that of the commercial carotene sample.

Similar to the light, when exposed to oxygen, the antioxidant capacity of the commercial sample decreased sharply from $75.66 \%$ to $47.08 \%$ for the first $4 \mathrm{~h}$ (a decrease of about 28.58\%) and continued to decrease to $44.02 \%$ for the next $4 \mathrm{~h}$. However, the antioxidant capacity of the microencapsulated $\beta$-carotene samples decreased from $69.07 \%$ to $59.50 \%$ (a decrease of $9.57 \%$ ) for the first $4 \mathrm{~h}$ of exposure to oxygen, and the antioxidant capacity decreased slightly for the next $4 \mathrm{~h}$. Thus, it can be clearly seen that the effect 
$\square$ free beta-ca rotene

。ํำ
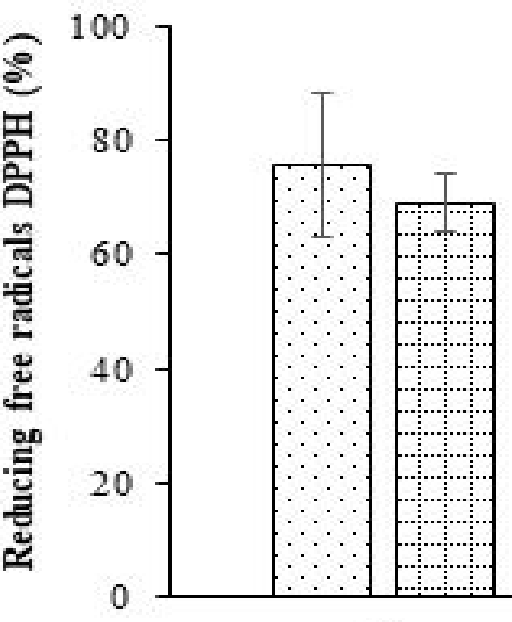

7microen cap sulated beta-carotene

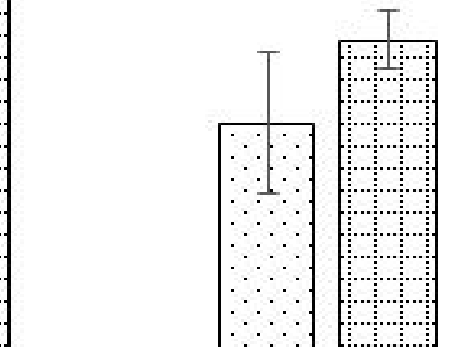

0

4

\section{Exposure time (h)}

Figure 2. The effect of light on the antioxidant capacity of $\beta$-carotene.

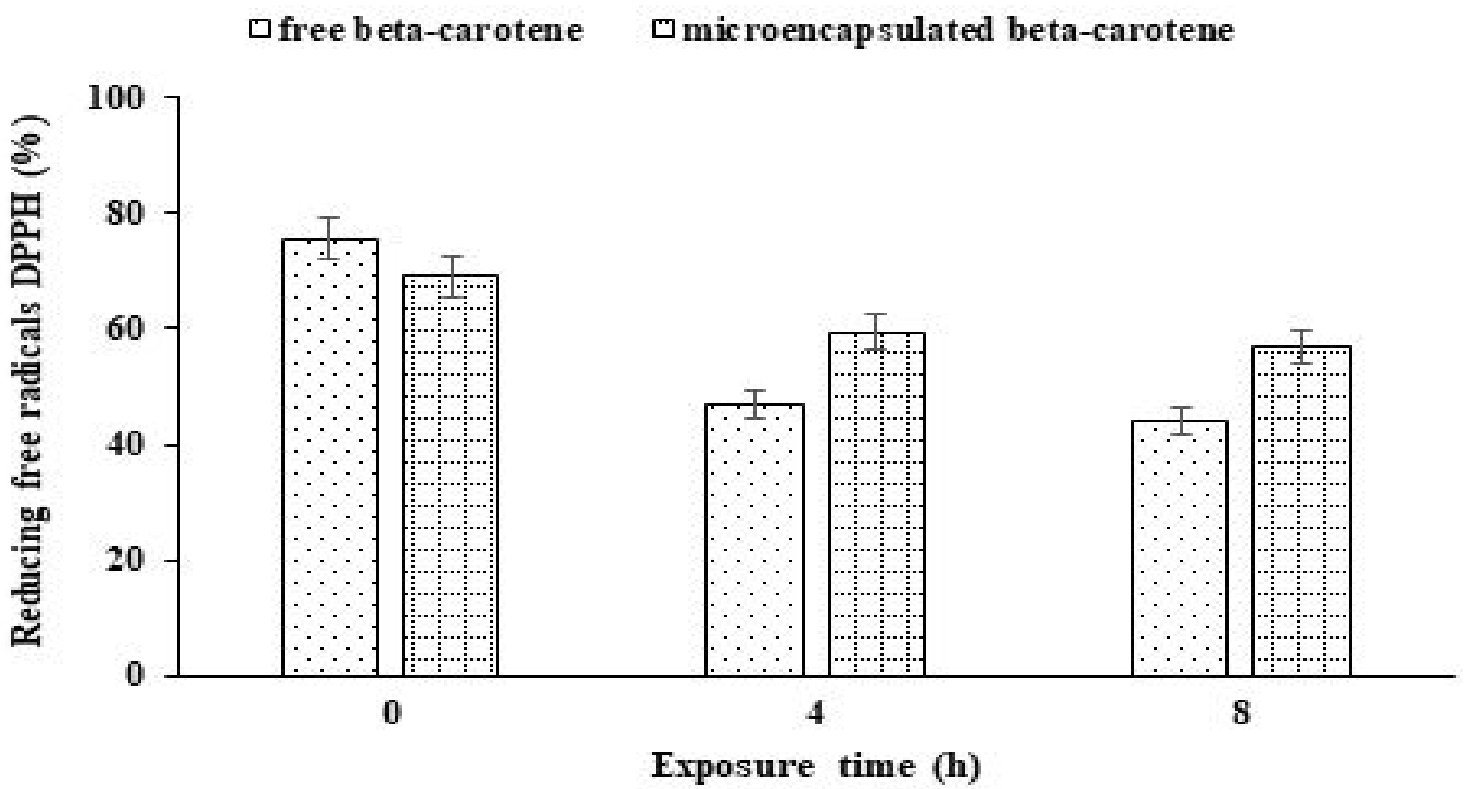

Figure 3. The effect of oxygen on the antioxidant capacity of microencapsulated $\beta$-carotene powder.

of oxygen on microencapsulated carotene in powder samples was lower than that of commercial carotene samples.

\subsection{Microstructure of the microencapsulated $\beta$-carotene powder}

The color of the spray-dried powder was offwhite. The microstructure of the encapsulated $\beta$-carotene powders observed using SEM is presented in Figure 4. The SEM results showed that the microencapsulation of $\beta$-carotene with only MD created the spherical particles, including smooth and concave surfaces. In comparison with the microencapsulation of $\beta$-carotene with the combination of MD and PS, there were more concave surfaces created. It could be explained that a great pressure during the spray- 

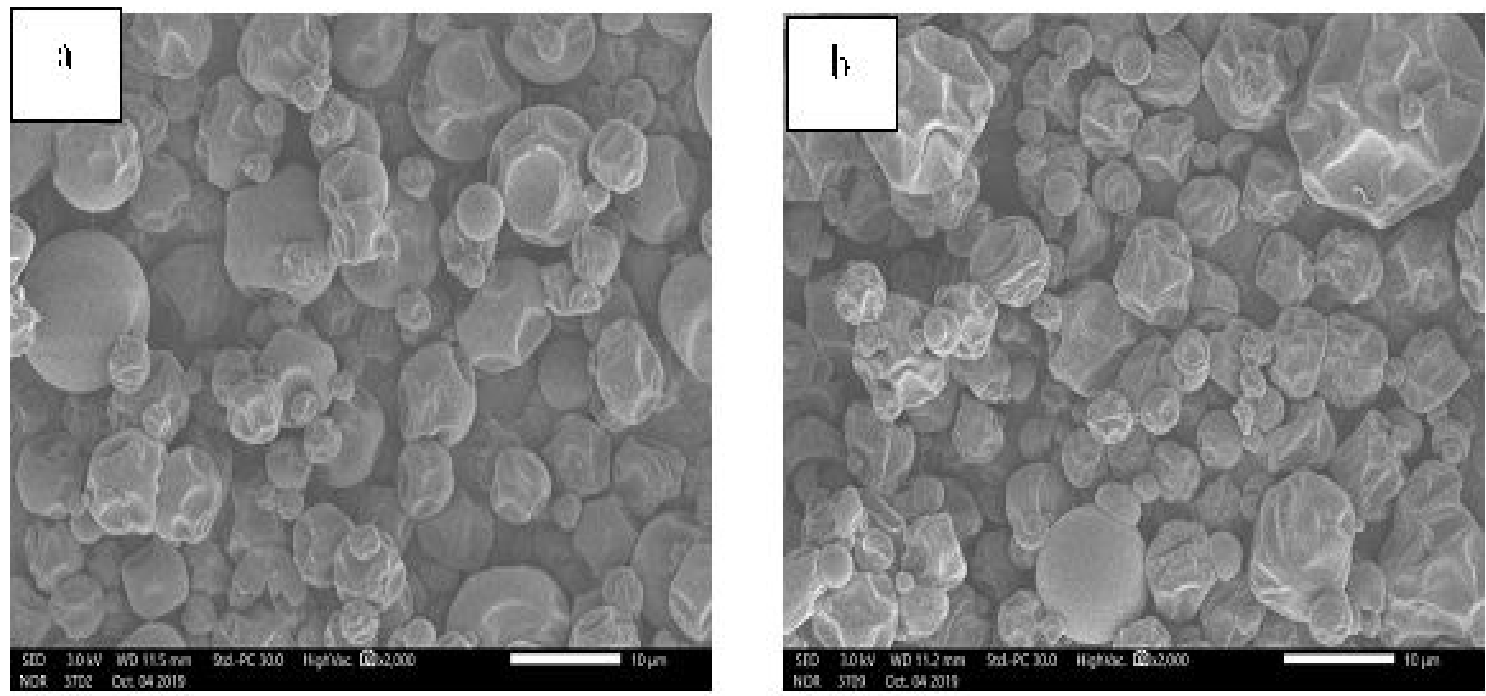

Figure 4. SEM microstructure of spray-dried encapsulated powders (a: maltodextrin, b: maltodextrin + polysaccharides). SEM: Scanning electron microscopy.

drying process could cause the particle's surfaces become convex and concave differently. The sizes of microencapsulated particles were not uniform as well. The SEM results were also quite similar to the study of Loksuwan (2007). The less concave surfaces of MD were created because these types of sugar having low molecular weight could act as a plasticizer to prevent the surface shrinkage during the spray drying process. According to Ye et al. (2000) plastics are very important to the formation of spherical microscopic capsules having smooth surfaces.

\section{Conclusions}

In conclusion, the effects of wall material (PS and $\mathrm{MD}$ ) concentration, homogenization time and inlet air temperature of spray drying on the properties of the encapsulated $\beta$-carotene powder were investigated. MEY, MEE and antioxidant capacity were significantly affected by those parameters. High MEE in terms of high retention of $\beta$-carotene in the powder could be obtained when the initial solution containing PS and MD as wall material was homogenized for $15 \mathrm{~min}$ and spray dried at the inlet temperature of $150^{\circ} \mathrm{C}$. The encapsulated $\beta$-carotene powder was found to be stable under exposure to light and oxygen due to low moisture content and free of cracks and pores as compared to the commercial one. The resultant powder could be then incorporated in to various foods for health benefits.

\section{Acknowledgement}

The authors acknowledge Ho Chi Minh City University of Food Industry for the financial support for this research, and thank you the student Nguyen Huynh Thao Ngan for her analytical assistance.

\section{References}

Brand-Williams, W., Cuvelier, M. E., \& Berset, C. (1995). Use of a free radical method to evaluate antioxidant activity. LWT-Food science and Technology 28(1), 25-30.

Bzducha-Wróbel, A., Błażejak, S., Kawarska, A., StasiakRóżańska, L., Gientka, I., \& Majewska, E. (2014). Evaluation of the efficiency of different disruption methods on yeast cell wall preparation for $\beta$-glucan isolation. Molecules 19(12), 20941-20961.

Czerniak, A., Kubiak, P., Białas, W., \& Jankowski, T. (2015). Improvement of oxidative stability of menhaden fish oil by microencapsulation within biocapsules formed of yeast cells. Journal of Food Engineering 167, 2-11.

Gharsallaoui, A., Roudaut, G., Chambin, O., Voilley, A., \& Saurel, R. (2007). Applications of spray-drying in microencapsulation of food ingredients: An overview. Food Research International 40(9), 1107-1121.

Golovina, E. A., Golovin, A., Hoekstra, F., \& Faller, R. (2010). Water replacement hypothesis in atomic details: effect of trehalose on the structure of single dehydrated POPC bilayers. Langmuir 26(13), 11118-11126.

Kha, T. C., Nguyen, M. H., \& Roach, P. D. (2010). Effects of spray drying conditions on the physicochemical and antioxidant properties of the Gac (Momordica 
cochinchinensis) fruit aril powder. Journal of Food Engineering 98(3), 385-392.

Kha, T. C., Nguyen, M. H., Roach, P. D., \& Stathopoulos, C. E. (2014). Microencapsulation of Gac oil: Optimisation of spray drying conditions using response surface methodology. Powder Technology 264, 298-309.

Kogan, G., \& Kocher, A. (2007). Role of yeast cell wall polysaccharides in pig nutrition and health protection. Livestock Science 109(1), 161-165.

Loksuwan, J. (2007). Characteristics of microencapsulated $\beta$-carotene formed by spray drying with modified tapioca starch, native tapioca starch and maltodextrin. Food Hydrocolloids 21(5), 928-935.

Nazzaro, F., Orlando, P., Fratianni, F., \& Coppola, R. (2012). Microencapsulation in food science and biotechnology. Current Opinion in Biotechnology 23(2), 182-186.

Paramera, E. I., Konteles, S. J., \& Karathanos, V. T. (2011). Microencapsulation of curcumin in cells of Saccharomyces cerevisiae. Food Chemistry 125(3), 892902.

Pham-Hoang, B. N., Romero-Guido, C., Phan-Thi, H., \& Waché, Y. (2018). Strategies to improve carotene entry into cells of Yarrowia lipolytica in a goal of encapsulation. Journal of Food Engineering 224, 88-94.

Rodriguez-Amaya, D. B. (2001). A guide to carotenoid analysis in foods. Washington, USA: ILSI press Washington.

Shappley, Z., Jenkins, J. N., Zhu, J., \& McCarty, Jr., J. C. (1998). Quantitative trait loci associated with agronomic and fiber traits of upland cotton. The Journal of Cotton Science 2, 153-163.
Shi, G., Rao, L., Yu, H., Xiang, H., Yang, H., \& Ji, R. (2008). Stabilization and encapsulation of photosensitive resveratrol within yeast cell. International Journal of Pharmaceutics 349(1), 83-93.

Shu, B., Yu, W., Zhao, Y., \& Liu, X. (2006). Study on microencapsulation of lycopene by spray-drying. Journal of Food Engineering 76(4), 664-669.

Sultana, A., Tanaka, Y., Fushimi, Y., \& Yoshii, H. (2018). Stability and release behavior of encapsulated flavor from spray-dried Saccharomyces cerevisiae and maltodextrin powder. Food Research International 106, 809-816.

Sun-Waterhouse, D., Penin-Peyta, L., Wadhwa, S. S., \& Waterhouse, G. I. N. (2011). Storage stability of phenolic-fortified avocado oil encapsulated using different polymer formulations and co-extrusion technology. Food and Bioprocess Technology 5(8), 3090-3102.

Tonon, R. V., Brabet, C., \& Hubinger, M. D. (2008). Influence of process conditions on the physicochemical properties of açai (Euterpe oleraceae Mart.) powder produced by spray drying. Journal of Food Engineering 88(3), 411-418.

Wagner, L. A., \& Warthesen, J. J. (1995). Stability of spray-dried encapsulated carrot carotenes. Journal of Food Science 60(5), 1048-1053.

Ye, X., Al-Babili, S., Klöti, A., Zhang, J., Lucca, P., Beyer, P., \& Potrykus, I. (2000). Engineering the provitamin A ( $\beta$-carotene) biosynthetic pathway into (carotenoid-free) rice endosperm. Science 287(5451), 303-305. 